\title{
Comparison of the effectiveness and safety of a new de-airing technique with a standardized carbon dioxide insufflation technique in open left heart surgery: A randomized clinical trial
}

\author{
Faleh Al-Rashidi, MD, ${ }^{a}$ Maya Landenhed, MD, ${ }^{a}$ Sten Blomquist, MD, PhD, ${ }^{\mathrm{b}}$ Peter Höglund, MD, PhD, ${ }^{\mathrm{c}}$ \\ Per-Axel Karlsson, EBCP, ${ }^{\mathrm{a}}$ Leif Pierre, CCP, BSc, ${ }^{\mathrm{a}}$ and Bansi Koul, MD, PhD ${ }^{\mathrm{a}}$
}

\begin{abstract}
Objective: We have compared the effectiveness, time required for de-airing, and safety of a newly developed de-airing technique for open left heart surgery (Lund technique) with a standardized carbon dioxide insufflation technique.
\end{abstract}

\begin{abstract}
Methods: Twenty patients undergoing elective open aortic valve surgery were randomized prospectively to the Lund technique (Lund group, $\mathrm{n}=10$ ) or the carbon dioxide insufflation technique (carbon dioxide group, $\mathrm{n}=10$ ). Both groups were monitored intraoperatively during de-airing and for 10 minutes after weaning from cardiopulmonary bypass by transesophageal echocardiography and online transcranial Doppler for the severity and the number of gas emboli, respectively. The systemic arterial partial pressure of carbon dioxide and $\mathrm{pH}$ were also monitored in both groups before, during, and after cardiopulmonary bypass.
\end{abstract}

Results: The severity of gas emboli observed on transesophageal echocardiography and the number of microembolic signals recorded by transcranial Doppler were significantly lower in the Lund group during the de-airing procedure $(P=.00634)$ and in the first 10 minutes after weaning from cardiopulmonary bypass $(P=.000377)$. Furthermore, the de-airing time was significantly shorter in the Lund group ( 9 vs 15 minutes, $P=.001$ ). The arterial $\mathrm{pH}$ during the cooling phase of cardiopulmonary bypass was significantly lower in the carbon dioxide group $(P=.00351)$, corresponding to significantly higher arterial partial pressure of carbon dioxide $(P=.005196)$ despite significantly higher gas flows $(P=.0398)$ in the oxygenator throughout the entire period of cardiopulmonary bypass.

Conclusions: The Lund de-airing technique is safer, simpler, and more effective compared with the carbon dioxide insufflation technique. The technique is also more cost-effective because the de-airing time is shorter and no extra expenses are incurred. (J Thorac Cardiovasc Surg 2011;141:1128-33)

Systemic air embolism as seen on transesophageal echocardiography (TEE) occurs frequently during open surgery despite improvements in surgical and cardiopulmonary bypass (CPB) techniques. ${ }^{1-4}$ The main source of these air emboli is the pulmonary veins. ${ }^{5}$ These air emboli continue to show on TEE for as long as 28 minutes after weaning from CPB and are one of the contributing factors for neurocognitive adverse events. ${ }^{3,6,7}$ In addition, they can cause transient and permanent neurologic deficits and induce ventricular dysfunction and life-threatening arrhythmias. ${ }^{7-10}$ Various de-airing techniques, such as the Trendelenburg position of the patient, partial side clamping of the ascending aorta,

\footnotetext{
From the Departments of Cardiothoracic Surgery, ${ }^{\text {a }}$ Cardiothoracic Anesthesia and Intensive Care, ${ }^{\mathrm{b}}$ and Clinical Research and Competence Center, ${ }^{\mathrm{c}}$ Skane University Hospital in Lund, University of Lund, Sweden.

Disclosures: Authors have nothing to disclose with regard to commercial support.

Received for publication April 1, 2010; revisions received June 7, 2010; accepted for publication July 3, 2010; available ahead of print Sept 3, 2010.

Address for reprints: Bansi Koul, MD, PhD, Cardiothoracic Surgery, A Block, Floor 8, Skane University Hospital in Lund, 22185 Lund, Sweden (E-mail: bansi.koul@ skane.se).

$0022-5223 / \$ 36.00$

Copyright (c) 2011 by The American Association for Thoracic Surgery doi:10.1016/j.jtcvs.2010.07.013
}

and flooding of the cardiothoracic cavity with $\mathrm{CO}_{2}$, are frequently used in combination with different vents to evacuate the retained air in the left side of the heart. ${ }^{11-14}$ However, the results are not optimal. ${ }^{1,15-17}$ Transcranial Doppler (TCD) studies have revealed that large amounts of cerebral microembolic signals (MES) are recorded during the de-airing process, particularly when the heart starts to eject blood into the systemic arterial circulation. ${ }^{14,18}$ Recent reports have shown that insufflation of $\mathrm{CO}_{2}$ into the cardiothoracic cavity reduces systemic air embolism significantly during open surgery. ${ }^{19-21}$ However, there is a potential hazard of $\mathrm{CO}_{2}$-induced systemic acidosis from prolonged insufflation of $\mathrm{CO}_{2}$ in the operating field. ${ }^{22}$

We have developed a de-airing technique that was shown to be significantly better than the conventional manual de-airing technique. ${ }^{18,23}$ We have now compared the effectiveness and safety of our de-airing technique with a standardized $\mathrm{CO}_{2}$ insufflation technique in routine open left heart surgery using intraoperative TEE, TCD, and blood gas analyses.

\section{MATERIALS AND METHODS}

After approval by the hospital ethical committee, the study was registered under the online protocol registration system with clinical trial registry 

Abbreviations and Acronyms
$\mathrm{CO}_{2}=$ carbon dioxide
$\mathrm{CPB}=$ cardiopulmonary bypass
$\mathrm{LV}=$ left ventricle
MES $=$ microembolic signals
$\mathrm{pCO}_{2}=$ partial pressure of $\mathrm{CO}_{2}$
$\mathrm{TCD}=$ transcranial Doppler
TEE $=$ transesophageal echocardiography

ID: NCT00934596. Patients scheduled for elective open aortic surgery were included in the study, and an informed consent was obtained from all patients. The following exclusion criteria were applied for all prospective patients: history of carotid artery disease, chronic obstructive pulmonary disease, emphysema, previous thoracic surgery, thoracic trauma, and concomitant left internal thoracic artery grafting. The following intraoperative exclusion criteria were applied: accidental opening of the pleurae during sternotomy in the $\mathrm{CO}_{2}$ group, failure to wean from $\mathrm{CPB}$, and failure to obtain adequate Doppler signals from the middle cerebral arteries. Twenty consecutive patients were randomized to the Lund de-airing technique (Lund group, $\mathrm{n}=10)$ or the $\mathrm{CO}_{2}$ insufflation technique $\left(\mathrm{CO}_{2}\right.$ group, $\mathrm{n}=10$ ). The randomization list was computer generated using the Statistical Analysis System Plan procedure (SAS ver 8.2 proc PLAN SAS Institute, Cary, NC). For each patient, an envelope indicating the de-airing technique to be used was opened in the operating room during induction of anesthesia.

The patients' demographic data are shown in Table 1. The patients were anesthetized and monitored during surgery in a standard manner using intraoperative TEE for all patients. The same ventilator machine was used for both groups during the intraoperative course (Servo-i, Maquet Inc, Solna, Sweden). Surgery was performed using standard median sternotomy. $\mathrm{CPB}$ was performed for all patients using a membrane oxygenator (Compact Flow EVO Phiso; Sorin Group USA Inc, Arvada, Colo), an arterial filter (Cobe Century, Sorin Group USA Inc), and polyvinylchloride tubing (silicone tubing in the pump heads). Roller pumps (Stöckert S3, Sorin Group USA Inc) and a heat exchanger (T3, Sorin Group USA Inc) were used in all patients. The right atrium was cannulated for venous drainage, and arterial blood was returned to the aorta. The CPB was established with a continuous blood flow rate of approximately $2.5 \mathrm{~L} / \mathrm{min} / \mathrm{m}^{2}$ at normothermia. During CPB, patients were cooled to $28^{\circ} \mathrm{C}$ to $25^{\circ} \mathrm{C}$. All patients received antegrade cold blood cardioplegia. The left ventricle (LV) was vented through the apex in all patients using a $15 \mathrm{~F}$ Polystan LV drainage catheter (Maquet, Solna, Sweden). The vent was prevented from causing accidental suction collapse of the left side of the heart by piercing the vent line with a $1.20 \times 50$-mm gauge aspiration needle (B-Braun Melsungen A/G, Germany) and leaving the needle in situ.

\section{Lund De-Airing Technique}

Before CPB was started, both pleural cavities were exposed to atmospheric air through small openings in the mediastinal pleurae. After CPB was established the patient was disconnected from the ventilator, allowing both lungs to collapse. After completion of the surgical procedure and closure of the heart, the LV vent was clamped and the aortic root was de-aired. In this study, we modified our previously described de-airing technique ${ }^{18,23}$ by applying active suction of the aortic root until it completely collapsed before the release of the aortic crossclamp (Lund technique). The aortic crossclamp was then released and the LV vent opened again. The heart was then defibrillated to sinus- or pacemaker-induced rhythm. After a good cardiac contraction and normal central hemodynamics, the LV preload was gradually and successively increased by reducing the venous return to the CPB circuit, and the vent in the LV-apex increased under TEE
TABLE 1. Patient demography and preoperative clinical data by group (values shown are median with upper and lower quartiles for continuous variables)

\begin{tabular}{lccc}
\hline & $\begin{array}{c}\text { Lund group } \\
(\mathbf{n}=\mathbf{1 0})\end{array}$ & $\begin{array}{c}\mathbf{C O}_{2} \text { group } \\
(\mathbf{n}=\mathbf{1 0})\end{array}$ & $\begin{array}{c}\boldsymbol{P} \\
\text { value }\end{array}$ \\
\hline Age $(\mathrm{y})$ & $70(59-77)$ & $71(56-78)$ & $.942^{*}$ \\
Male/female & $5 / 5$ & $5 / 5$ & $1.0 \dagger$ \\
Weight $(\mathrm{kg})$ & $72(65-86)$ & $80(71-90)$ & $.511^{*}$ \\
Height $(\mathrm{cm})$ & $176(169-182)$ & $172(162-181)$ & $.487^{*}$ \\
Body surface area $\left(\mathrm{m}^{2}\right)$ & $1.85(1.76-2.06)$ & $2.0(1.76-2.16)$ & $.743^{*}$ \\
Plasma creatinine & $73(67-84)$ & $66(64-83)$ & $.559^{*}$ \\
$\quad$ preoperative $(\mu \mathrm{mol} / \mathrm{L})$ & & & $.006^{*}$ \\
Plasma ASAT & $0.49(0.44-0.54)$ & $0.36(0.32-0.44)$ & \\
$\quad$ preoperative $(\mu \mathrm{kat} / \mathrm{L})$ & & & $.03^{*}$ \\
Plasma ALAT & $0.50(0.42-0.59)$ & $0.29(0.26-0.41)$ & \\
$\quad$
\end{tabular}

preoperative $(\mu \mathrm{kat} / \mathrm{L})$

$A S A T$, Aspartate amino transaminase; $A L A T$, alanine amino transaminase; $\mathrm{CO}_{2}$, carbon dioxide. *Wilcoxon rank-sum test. †Fisher's exact test.

monitoring to prevent cardiac ejection. When no air emboli were observed in the left side of the heart, the patient was reconnected to the ventilator and the lungs were ventilated with half of the estimated minute volume using $100 \%$ oxygen and $5 \mathrm{~cm} \mathrm{H}_{2} \mathrm{O}$ positive end-expiratory pressure. The deairing was continued, and when no air emboli were observed in the left side of the heart, the lungs were ventilated to full capacity and the heart was allowed to eject by reducing the LV vent. The time from the release of the aortic crossclamp to the cardiac ejection was noted (de-airing time before cardiac ejection, Table 2). The de-airing was continued, and the patient was weaned from CPB. The LV vent was clamped in situ provided that TEE continued to show no air emboli in the left side of the heart, and the time was noted again (de-airing time after cardiac ejection, Table 2).

\section{Carbon Dioxide Insufflation Technique}

The pleural cavities were left intact in the $\mathrm{CO}_{2}$ group. During CPB, the patient was ventilated with a minute volume of $1 \mathrm{~L}$, at a frequency of 5 per minute and with a positive end-expiratory pressure of $5 \mathrm{~cm} \mathrm{H}_{2} \mathrm{O}$. Before the cannulation for $\mathrm{CPB}$, the $\mathrm{CO}_{2}$ insufflation was accomplished as follows: $\mathrm{CO}_{2}$ was insufflated into the cardiothoracic wound through a gas diffuser (Cardia Innovation $\mathrm{AB}$ ) that provided an approximately $100 \% \mathrm{CO}_{2}$ atmosphere in the wound. ${ }^{24}$ The diffuser was placed in the sternotomy wound at a depth of $5 \mathrm{~cm}$ below the skin adjacent to the diaphragm. $\mathrm{CO}_{2}$ flow was set at $10 \mathrm{~L} / \mathrm{min}$ and continued until 10 minutes post-CPB. Use of coronary and vent suction was restricted to a minimum to maintain adequate $\mathrm{CO}_{2}$ concentration in the cardiothoracic cavity. Care was also taken to ensure that the diffuser was not soaked with blood during the course of surgery. After completion of the surgical procedure and closure of the heart, the heart and lungs were passively filled with blood from the $\mathrm{CPB}$ circuit. The heart was massaged gently, and the left side was de-aired continuously through the LV apical vent. Full ventilation was then resumed, the LV vent was clamped, and the aortic root was de-aired by active suctioning until it collapsed completely. The aortic crossclamp was then released, and the LV vent was opened again. The heart was defibrillated to sinus- or pacemaker-induced rhythm. After good cardiac contraction and normal central hemodynamics were achieved, the LV preload was gradually and successively increased by reducing the venous return to the CPB circuit, and the de-airing continued through the vent in the LV apex under TEE monitoring. When no gas emboli were observed in the left side of the heart, the LV vent was reduced and the heart was allowed to eject; the time was noted (de-airing time before cardiac ejection, Table 2). De-airing was continued, and when no further gas emboli were observed in the left side of the heart, the patient was weaned from CPB and the LV vent was clamped in situ. The time was noted again (de-airing time after cardiac ejection, Table 2). 
TABLE 2. Clinical intra- and perioperative data by group (values shown are median with upper and lower quartiles for continuous variables)

\begin{tabular}{|c|c|c|c|c|}
\hline & $\mathbf{n}$ & $\begin{array}{l}\text { Lund group } \\
\quad(\mathbf{n}=10)\end{array}$ & $\begin{array}{c}\mathrm{CO}_{2} \text { group } \\
(\mathbf{n}=\mathbf{1 0})\end{array}$ & $\begin{array}{c}P \\
\text { value }\end{array}$ \\
\hline \multicolumn{5}{|l|}{ Original surgical procedures: 20} \\
\hline - Aortic valve replacement & & $7(70 \%)$ & $6(60 \%)$ & \\
\hline - Aortic valve repair & & $1(10 \%)$ & $3(30 \%)$ & \\
\hline - Bentall operation & & $2(20 \%)$ & $1(10 \%)$ & \\
\hline \multicolumn{5}{|l|}{ Concomitant procedures: } \\
\hline $\begin{array}{l}\text { - Ascending aorta } \\
\text { replacement }\end{array}$ & & $2(20 \%)$ & $1(10 \%)$ & \\
\hline - Aortic arch replacement & & 0 & $1(10 \%)$ & \\
\hline $\begin{array}{l}\text { - Aortic annulus } \\
\text { enlargement }\end{array}$ & & $2(20 \%)$ & 0 & \\
\hline $\begin{array}{l}\text { - Coronary artery bypass } \\
\text { grafting }\end{array}$ & & $2(20 \%)$ & $1(10 \%)$ & \\
\hline - Maze procedure & & $1(10 \%)$ & 0 & \\
\hline $\mathrm{CPB}$ time (min) & 20 & $117(105-135)$ & $94(84-154)$ & .252 \\
\hline Aortic crossclamp time (min) & 20 & $89(77-108)$ & $59(52-88)$ & .074 \\
\hline Total de-airing time $(\mathrm{min})$ & 20 & $9(8-10)$ & $15(11-16)$ & .001 \\
\hline $\begin{array}{l}\text { - De-airing time before } \\
\text { cardiac ejection }\end{array}$ & 20 & $6(4-7)$ & $7(5-10)$ & .334 \\
\hline $\begin{array}{l}\text { - De-airing time after } \\
\text { cardiac ejection }\end{array}$ & 20 & $3(2-3)$ & $5(4-8)$ & .002 \\
\hline Ventilator time (h) & 20 & $6(4-8)$ & $6(4-7)$ & .882 \\
\hline Intensive care unit stay (h) & 20 & $21(20-22)$ & $22(21-24)$ & .293 \\
\hline Hospital stay (d) & 20 & $7(7-8)$ & $7(6-7)$ & .239 \\
\hline $\begin{array}{l}\text { Plasma creatinine } \\
\text { postoperative }(\mu \mathrm{mol} / \mathrm{L})\end{array}$ & 20 & $72(64-87)$ & $55(52-74)$ & .155 \\
\hline $\begin{array}{l}\text { Plasma ASAT } \\
\text { postoperative }(\mu \mathrm{kat} / \mathrm{L})\end{array}$ & 20 & $1.13(0.87-1.48)$ & $0.83(0.79-0.95)$ & .18 \\
\hline $\begin{array}{l}\text { Plasma ALAT } \\
\text { postoperative }(\mu \mathrm{kat} / \mathrm{L}\end{array}$ & 20 & $0.73(0.44-1.08)$ & $0.32(0.29-0.39)$ & .056 \\
\hline
\end{tabular}

$A S A T$, Aspartate amino transaminase; $A L A T$, alanine amino transaminase; $C P B$ cardiopulmonary bypass. Test used: Wilcoxon rank-sum test.

The patients were monitored continuously for gas emboli in the left side of the heart and MES from the middle cerebral arteries for 10 minutes after weaning from CPB using TEE and TCD, respectively. During this period, the $\mathrm{LV}$ vent and $\mathrm{CPB}$ cannulas were left clamped in situ. After a 10-minute period (10 minutes after $\mathrm{CPB}$, Table 2), CPB was restarted to remove the LV vent followed by venous and arterial cannulas. Pleural drains were placed only if pleurae were widely opened for reasons other than de-airing in the Lund group.

\section{Transesophageal Echocardiography}

Directly after weaning from the CPB, the left atrium, LV, and ascending aorta were monitored continuously for 10 minutes by TEE (Philips HP Sonos 5500, Andover, MA) using a 3-chamber view for residual air. The echocardiogram for each individual patient was recorded on a videotape and analyzed at the end of the study by 1 senior cardiac anesthesiologist who was blinded to the de-airing technique used, TCD findings, and the blood gas analysis results.

The severity of air emboli observed on TEE was classified in 4 grades as follows ${ }^{18}$ :

- grade 0 , no residual air emboli;

- grade I, air emboli observed in left atrium only during 1 cardiac cycle;
- grade II, air emboli observed simultaneously in the left atrium and LV during 1 cardiac cycle; and

- grade III, air emboli observed simultaneously in the left atrium, LV, and aortic root during 1 cardiac cycle.

To assess the severity and the progress of air emboli, the 10-minute observation period was further subdivided into 3 intervals: the first 3 minutes, the second 3 minutes, and the last 4 minutes. During the de-airing, the LV was vented intermittently whenever the TEE air emboli exceeded grade II, and the events were noted for all individual patients.

\section{Transcranial Doppler Monitoring}

Middle cerebral arteries on both sides were monitored continuously for MES using multifrequency TCD scanning (Doppler box; DWL, Singen, Germany) during the de-airing procedure itself and for the first 10 minutes after weaning from CPB. The bilateral probes were fixed transtemporally by a head brace, and all MES were counted online automatically. The detection level for MES was an increase in power of more than $10 \mathrm{~dB}$ above background level and an embolus blood ratio that lasted $4 \mathrm{~ms}$ or longer simultaneously in both the 2.0-M and 2.25-M frequency channels. The insonation and reference gate depths were between 50 and $60 \mathrm{~mm}$, sample volume was $10 \mathrm{~mm}$, filter setting was $150 \mathrm{~Hz}$, power was $180 \mathrm{~mW}$, and gain was 10 . The multifrequency Doppler has a sensitivity of $98.6 \%$ and specificity of $97.2 \%$ for detection of MES and artifacts. ${ }^{25}$

During CPB, arterial blood samples were drawn for analysis of the blood gases every 15 minutes (Radiometer, Copenhagen, Denmark). Arterial pH and arterial partial pressure of $\mathrm{CO}_{2}\left(\mathrm{pCO}_{2}\right)$ were also monitored continuously from the arterial line as they left the oxygenator using an online CDI 500 (Terumo Cardiovascular System, Ann Arbor, MI). The gas flow in the oxygenator was readjusted when the arterial $\mathrm{pCO}_{2}$ was lower than $5.5 \mathrm{kPa}$ or higher than $6.5 \mathrm{kPa}$ to correct the arterial $\mathrm{pH}$ and $\mathrm{pCO}_{2}$. These data were also recorded every 15 minutes. The results of the blood gas analysis were corrected to the actual temperature of the patients $(\alpha$-STAT).

\section{Statistics}

Data were analyzed using the stat and Hmisc packages of the R software (R Foundation for Statistical Computing, Vienna, Austria), version 2.6.0. Counts in cross-tabs were compared using Fisher's exact test. Continuous variables are presented as medians and quartiles, and the Wilcoxon ranksum test was used for comparison. Poisson regression was used to test for the number of times the LV vent was opened in both groups during the first 10 minutes after CPB termination for TEE grade III gas emboli.

\section{RESULTS}

The intraoperative and perioperative clinical data are summarized in Table 2 . The total de-airing time was significantly shorter $(P<.001)$ in the Lund group mainly because of a shorter de-airing time after the heart was allowed to eject. In the Lund group, all 10 patients $(100 \%)$ had TEE grade I or lower gas emboli during the first post-CPB 3-minute interval compared with 4 patients $(40 \%)$ in the $\mathrm{CO}_{2}$ group $(P=.00634$, Figure 1$)$. In the second post-CPB 3-minute interval, 9 patients $(90 \%)$ in the Lund group had TEE grade I or lower gas emboli compared with 7 patients $(70 \%)$ in the $\mathrm{CO}_{2}$ group $(P=.699$, Figure 1$)$. In the third post-CPB 4minute interval, 9 patients $(90 \%)$ in the Lund group continued to have TEE grade I or lower gas emboli compared with 7 patients $(70 \%)$ in the $\mathrm{CO}_{2}$ group $(P=.615$, Figure 1$)$. During this 10-minute post-CPB observation period, the LV vent was reopened in 1 patient $(10 \%)(0.3 \%-45 \%$, 

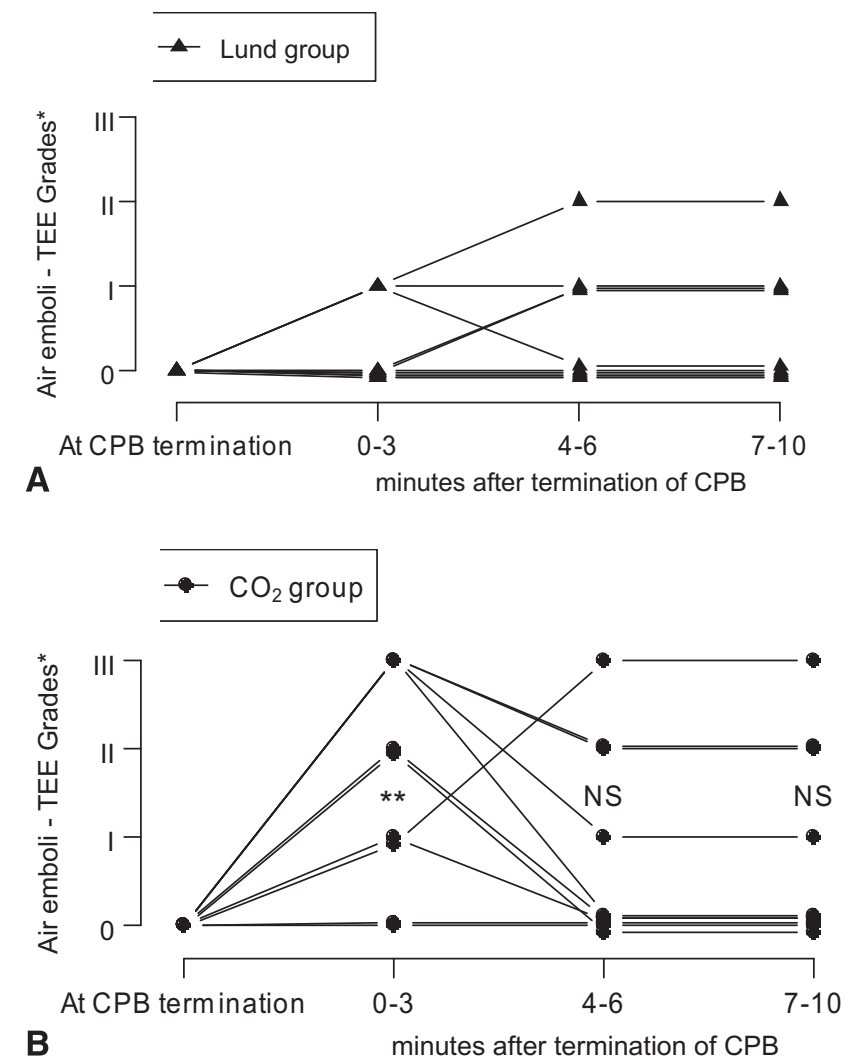

FIGURE 1. TEE 3-chamber view monitoring of gas emboli during the first 10 minutes after weaning from $\mathrm{CPB}$ in Lund (A) and $\mathrm{CO}_{2}(\mathrm{~B})$ groups. At the end of the first 3 minutes, a significantly higher $(P=.00634)$ number of patients showed grade I or more gas emboli in the $\mathrm{CO}_{2}$ group. * Grade 0 , no residual gas emboli; grade I, gas emboli observed in 1 of the 3 anatomic areas during 1 cardiac cycle (left atrium, LV, aortic root); grade II, gas emboli observed simultaneously in 2 of the 3 anatomic areas during 1 cardiac cycle; grade III, gas emboli observed simultaneously in all 3 anatomic areas during 1 cardiac cycle. TEE, Transesophageal echocardiography; $C P B$, cardiopulmonary bypass.

$95 \%$ confidence interval) in the Lund group compared with 4 patients $(40 \%)(12 \%-74 \%, 95 \%$ confidence interval $)$ in the $\mathrm{CO}_{2}$ group because of the appearance of TEE grade III gas emboli. Poisson regression on the number of the times the LV vent was reopened for the 2 groups $(2,0,0,0,0$, $0,0,0,0$ and 0 times in the Lund group and 3, 2, 1, 1, 0, $0,0,0,0$ and 0 times in the $\mathrm{CO}_{2}$ group) gave mean values of 0.2 and 0.7 , respectively $(P=.0816)$.

During the de-airing period, the total number of MES observed on TCD was significantly lower in the Lund group $(P=.0003772$, Figure 2$)$ mainly because of the reduced number of MES after the start of cardiac ejection. In the post-CPB 10-minute observation period, the number of cerebral MES observed in the Lund group was also significantly lower compared with the $\mathrm{CO}_{2}$ group $(P=.0005186$, Figure 2).

In the Lund group, a mild degree of right-sided weakness developed in 1 patient on the second postoperative day and recovered before discharge. This patient had received mediastinal radiotherapy previously for lymphoma, and his lungs failed to collapse and drop posteriorly when the respirator was disconnected. This was the only patient in the Lund group for whom the LV vent was reopened (twice) for TEE grade III gas emboli in the post-CPB 10-minute observation period. In the $\mathrm{CO}_{2}$ group, right arm weakness developed in 1 patient on the first postoperative day and recovered before discharge. This patient happened to be 1 of the 4 in the $\mathrm{CO}_{2}$ group for whom the LV vent was reopened (twice in this patient) for grade III gas emboli in the post-CPB 10-minute observation period.

During the initial hypothermic phase of CPB, systemic arterial $\mathrm{pH}$ was significantly lower in the $\mathrm{CO}_{2}$ group compared with the Lund group in the 15-, 30-, and 45-minute intervals ( $P=.00351, P=.000152$, and $P=.0203$ respectively). In the late near normothermic phase of $\mathrm{CPB}$ corresponding to the 15 - and 0 -minute intervals and during the first 15 minutes after weaning from $\mathrm{CPB}$, the systemic arterial $\mathrm{pH}$ remained lower in the $\mathrm{CO}_{2}$ group $(P=.1976, P=.1971$, and $P=.2538$, respectively). These changes in arterial $\mathrm{pH}$ corresponded inversely to the arterial $\mathrm{pCO}_{2}$ levels.

During $\mathrm{CPB}$, the gas flows to the oxygenator were readjusted to optimize arterial $\mathrm{pCO}_{2}$ readouts from the online CDI 500 monitor. At 30- and 45-minute intervals after the initiation of $\mathrm{CPB}$ (hypothermic phase), significantly higher gas flows to the oxygenator $(P=.0398$ and $P=.0124$ respectively) were required in the $\mathrm{CO}_{2}$ group to correct arterial $\mathrm{pCO}_{2}$ and respiratory acidosis. In the last two 15-minute intervals before the termination of CPB (near normothermic phase), the gas flows required in the oxygenator to optimize $\mathrm{pCO}_{2}$ were again significantly higher in the $\mathrm{CO}_{2}$ group ( $P=.0338$ and $P=.0305$, respectively). In the $\mathrm{CO}_{2}$ group, 1 patient developed postoperative mediastinitis that required vacuum-assisted closure treatment.

\section{DISCUSSION}

We modified our de-airing technique by applying active aortic root suction after completion of the left-sided heart procedure and before the aortic crossclamp was released. With this modification, the number of MES was reduced from a median of 58 (as determined in our earlier study ${ }^{18}$ ) to a median of 24 in the present study during the preejection phase of cardiac de-airing. We expected that the number of MES during the preejection phase of de-airing would be statistically similar in the 2 groups, because active aortic root suction was applied before the release of the aortic crossclamp in both groups. However, in the $\mathrm{CO}_{2}$ group, in contrast with the Lund group, the left side of the heart was passively filled with blood from the extracorporeal circuit first and the aortic crossclamp was released thereafter. Therefore, aortic root suction may not completely empty the aortic root because it is continuously fed with blood mixed with air or gas emboli from the LV. 


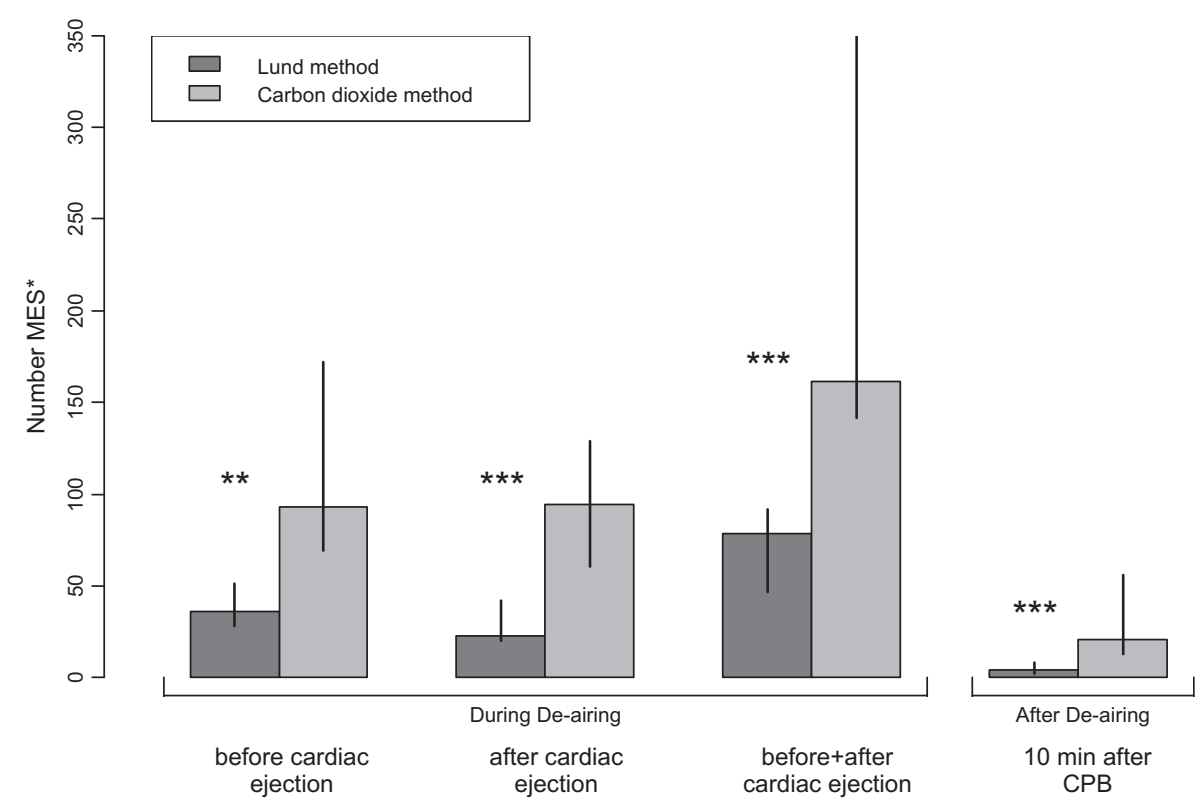

FIGURE 2. Number of MES as registered by TCD from both middle cerebral arteries during de-airing and the first 10-minute observation period after weaning from CPB. ${ }^{* * P}=.001699,{ }^{* * *} P=.0008768, .0003772$, and .0005186 in order of their appearance in the figure. MES, Microembolic signals; $C P B$, cardiopulmonary bypass.

The total de-airing time was significantly shorter in the Lund group compared with the $\mathrm{CO}_{2}$ group ( 9 vs 15 minutes, respectively, $P<.001$, Table 2 ). The preejection de-airing time was similar in both groups. In contrast, the postejection de-airing time was significantly shorter $(P<.002)$ in the Lund group, probably because of less air getting trapped in the pulmonary veins after induced passive collapse of the lungs. Furthermore, progressive cardiopulmonary filling with blood by right ventricular ejection and delayed and staged lung ventilation probably prevents existing air in the left side of the heart from entering the pulmonary veins as the de-airing continues. The MES as recorded by TCD showed a significantly lower number in the Lund group during the pre-ejection and postejection phases of de-airing $(P=.000377$, Figure 2).

After CPB, all patients in the Lund group showed TEE grade I or lower gas emboli after the first 3-minute interval compared with 4 patients $(40 \%)$ in the $\mathrm{CO}_{2}$ group $(P=.00634$, Figure 1$)$. After a 10 -minute interval post$\mathrm{CPB}, 9$ patients in the Lund group $(90 \%)$ showed TEE grade I or lower gas emboli compared with 7 patients $(70 \%)$ in the $\mathrm{CO}_{2}$ group. Moreover, during this period, the $\mathrm{LV}$ vent was reopened for TEE grade III gas emboli twice in 1 patient $(10 \%)$ in the Lund group compared with 4 patients $(40 \%)$ in the $\mathrm{CO}_{2}$ group. This corresponded well with the significantly higher number of MES recorded in the $\mathrm{CO}_{2}$ group, $(P=.0005186)$ during this period (Figure 2$)$. The de-airing model used in the present study permitted us to evacuate TEE grade III gas emboli through the LV apical vent as and when they showed on TEE during the post-CPB 10-minute period. Otherwise, the MES as recorded by TCD would have been higher in the $\mathrm{CO}_{2}$ group than what we actually recorded (Figure 2). These results demonstrate that the Lund de-airing technique is also more effective in reducing residual gas emboli after weaning from CPB $(P=.000377$, Figure 2$)$.

It can be argued that the MES as recorded by TCD in the $\mathrm{CO}_{2}$ group are composed of $\mathrm{CO}_{2}$ and not air, and therefore are less harmful to vital organs, including the brain. In an in vitro study, Svenarud and colleagues ${ }^{24}$ showed that with a $10 \mathrm{~L} / \mathrm{min}$ flow of $\mathrm{CO}_{2}$ through a diffuser placed $5 \mathrm{~cm}$ below the sternum, samples of gas taken from different places in the cardiothoracic cavity are composed of only $\mathrm{CO}_{2}$. However, even though $\mathrm{CO}_{2}$ is 25 times more soluble in blood than air, we continued to record MES on TCD in the $\mathrm{CO}_{2}$ group in statistically significant numbers even after a median of 25 minutes ( 15 minutes median de-airing time plus 10 minutes median post-CPB observation time) after the start of the de-airing procedure. This may indicate that some of these microemboli contain air and not $\mathrm{CO}_{2}$. It seems that in the operating room scenario, the concentration of insufflated $\mathrm{CO}_{2}$ in the cardiothoracic cavity keeps changing depending on the use of vents, cardiotomy suction, and surgeons' hand movements in the operating field. Entry of some quantity of air into the open left side of the heart is thereby unavoidable. However, when we compare the $\mathrm{CO}_{2}$ group in the present study with the conventional manual de-airing group from our previous study, ${ }^{18}$ the results are clearly superior in the $\mathrm{CO}_{2}$ group of the present study. This suggests that $\mathrm{CO}_{2}$ insufflation may be a suitable alternative to conventional manual de-airing in situations when passive 
pulmonary collapse cannot be achieved completely. Examples of such situations include patients with chronic obstructive pulmonary disease with or without emphysema, patients with unilateral or bilateral pulmonary adhesions for any reason, and patients undergoing minimally invasive left-sided heart valve procedures for whom access to pleural cavities may be difficult.

This study does not explain which aspect of the Lund technique is predominantly responsible for the improved outcomes regarding the de-airing, namely, (1) the passive pulmonary collapse of the lungs or (2) the staged pulmonary reperfusion and reventilation. We believe that both are perhaps equally important because both steps serve the same purpose, that is, preventing air in the left atrium from entering the pulmonary veins during different phases of surgery. Passive pulmonary collapse prevents air from entering the pulmonary veins when the left side of the heart, after CPB and cardioplegia, is exposed to the ambient air during open left heart surgery. TEE-controlled staged and progressive perfusion followed by staged ventilation prevents or minimizes any residual air in the left atrium from entering into empty or partially blood-filled expanding pulmonary veins and lungs during the de-airing process itself. The de-airing is finally almost always complete when the entire calculated cardiac output is restored through the native closed cardiopulmonary system.

The arterial $\mathrm{pH}$ was significantly lower and $\mathrm{pCO}_{2}$ was significantly higher in the $\mathrm{CO}_{2}$ group despite significantly higher gas flows in the oxygenator. The gas flows in the oxygenator were constantly adjusted to obtain optimal systemic arterial $\mathrm{pH}$ and $\mathrm{pCO}_{2}$ according to the online readouts from the CDI 500 monitor placed on the arterial line of the CPB. It is therefore likely that systemic arterial $\mathrm{pH}$ and $\mathrm{pCO}_{2}$ levels would have been higher in the $\mathrm{CO}_{2}$ group if we did not have the CDI 500 monitor on the arterial line of the CPB; therefore, we suggest that blood gases should be monitored closely when $\mathrm{CO}_{2}$ insufflation is used for de-airing purposes. Higher levels of systemic arterial $\mathrm{CO}_{2}$ are known to alter cerebral autoregulation by increasing blood flow to the brain and that could, in addition, enhance selective increased embolization of gas and particle emboli to the brain.

\section{CONCLUSIONS}

The Lund technique is safer, simpler, and more effective than the $\mathrm{CO}_{2}$ insufflation technique. Moreover, complete deairing can be achieved in a significantly shorter time and no extra equipment is needed for the procedure. Therefore, the Lund technique is also more cost-effective.

\section{References}

1. Dalmas JP, Eker A, Girard C, Flamens C, Neidecker J, Obadia JF, et al. Intracardiac air clearing in valvular surgery guided by transesophageal echocardiography. J Heart Valve Dis. 1996;5:553-7.
2. van der Linden J, Casimir-Ahn H. When do cerebral emboli appear during open heart operations? A transcranial Doppler study. Ann Thorac Surg. 1991;51: 237-41.

3. Tingleff J, Joyce FS, Pettersson G. Intraoperative echocardiographic study of air embolism during cardiac operations. Ann Thorac Surg. 1995;60:673-7.

4. Taylor RL, Borger MA, Weisel RD, Fedorko L, Fiendel CM. Cerebral microemboli during cardiopulmonary bypass: increased emboli during perfusionist interventions. Ann Thorac Surg. 1999;68:89-93.

5. Fishman NH, Carlsson E, Roe BB. The importance of the pulmonary veins in systemic air embolism following open-heart surgery. Surgery. 1969;66:655-62.

6. Pugsley W, Klinger L, Paschalis C, Treasure T, Harrison M, Newman S. The impact of microemboli during cardiopulmonary bypass on neuropsychological functioning. Stroke. 1994;25:1393-9.

7. Borger MA, Peniston CM, Weisel RD, Vasiliou M, Green REA, Fiendel CM. Neuropsychologic impairment after coronary bypass surgery: effect of gaseous microemboli during perfusionist interventions. J Thorac Cardiovasc Surg. 2001;121:743-9.

8. Abu-Omar Y, Cifelli A, Matthews PM, Taggart DP. The role of microembolisation in cerebral injury as defined by functional magnetic resonance imaging. Eur J Cardiothorac Surg. 2004;26:586-91

9. Bokeriia LA, Golukhova EZ, Breskina NY, Polunina AG, Davydov DM, Begachev AV, et al. Asymmetric cerebral embolic load and postoperative cognitive dysfunction in cardiac surgery. Cerebrovasc Dis. 2007;23:50-6.

10. Orihashi K, Matsuura Y, Sueda T, Shikata H, Mitsui N, Sueshiro M. Pooled air in open heart operations examined by transesophageal echocardiography. Ann Thorac Surg. 1996;61:1377-80.

11. Bagdonas AA, Stuckey JH, Dennis C, Piera J. Studies of the effects of position on the development of cerebral air embolism during open-heart surgery. Surgery. 1962;52:487-93

12. Rodriguez RA, Cornel G, Weerasena NA, Pham B, Splinter WM. Effect of Trendelenburg head position during cardiac deairing on cerebral microemboli in children: a randomized controlled trial. J Thorac Cardiovasc Surg. 2001; 121:3-9.

13. Thomas TV. Vents in open heart procedures: techniques and selection. J Cardiovasc Surg. 1971;12:366-70.

14. Martens S, Neumann K, Sodemann C, Deschka H, Wimmer-Greinecker G, Moritz A. Carbon dioxide field flooding reduces neurologic impairment after open heart surgery. Ann Thorac Surg. 2008;85:543-7.

15. Diehl JT, Ramos D, Dougherty F, Pandian NG, Payne DD, Cleveland RJ. Intraoperative, two-dimensional echocardiography-guided removal of retained intracardiac air. Ann Thorac Surg. 1987;43:674-5.

16. Duff HJ, Buda AJ, Kramer R, Strauss HD, David TE, Berman ND. Detection of entrapped intracardiac air with intraoperative echocardiography. Am J Cardiol. 1980;46:255-60

17. Orihashi K, Matsuura Y, Hamanaka Y, Sueda T, Shikata H, Hayashi S, et al Retained intracardiac air in open heart operations examined by transesophageal echocardiography. Ann Thorac Surg. 1993;55:1467-71.

18. Al-Rashidi F, Blomquist S, Höglund P, Meurling C, Roijer A, Koul B. A new de-airing technique that reduces systemic microemboli during open surgery: a prospective controlled study. J Thorac Cardiovasc Surg. 2009;138:157-62.

19. Svenarud P, Persson M, van der Linden J. Effect of CO2 insufflation on the number and behavior of air microemboli in open-heart surgery: a randomized clinical trial. Circulation. 2004;109:1127-32.

20. Kalpokas MV, Nixon IK, Kluger R, Beilby DS, Silbert BS. Carbon dioxide field flooding versus mechanical de-airing during open-heart surgery: prospective randomized Controlled trial. Perfusion. 2003;18:291-4.

21. Giordano S, Biancari F. Does the use of carbon dioxide field flooding during heart valve surgery prevent postoperative cerebrovascular complications? Interact Cardiovasc Thorac Surg. 2009;9:323-6.

22. MacRae WR, Masson AH, Owen JA, Campbell DG. Carbon dioxide acidosis during open heart surgery. Br J Anaesth. 1964;36:793-7.

23. Koul BL, Al-Rashidi F, Roijer A, Meurling C. A new technique to reduce residual air emboli in open left cardiac surgery. J Thorac Cardiovasc Surg. 2009;138: 1438-9.

24. Svenarud P, Persson M, van der Linden J. Intermittent or continuous carbon dioxide insufflation for de-airing of the cardiothoracic wound cavity? An experimental study with a new gas-diffuser. Anesth Analg. 2003;96:321-7.

25. Brucher R, Russell D. Automatic online embolus detection and artifact rejection with the first multifrequency transcranial Doppler. Stroke. 2002;33:1969-74. 